\title{
HAM-FISTED POLICIES, OVERWORKED OFFICIALS PUT FOREIGN DOCTORS 'ON ICE'
}

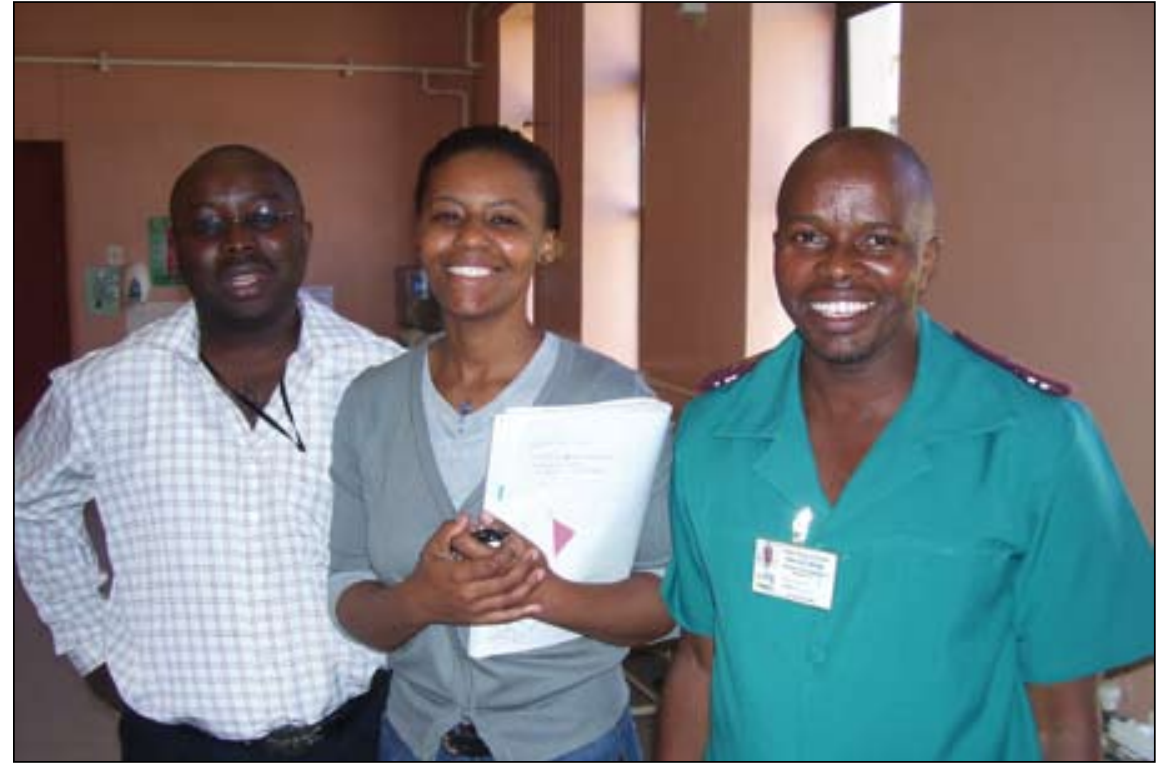

These two foreign qualified health care staff (flanking their South African colleague) help keep a deep rural KwaZulu-Natal hospital afloat.

Eager to work in South Africa's understaffed public hospitals, hundreds of foreign doctors with permanent local residence status have spent two years languishing 'on ice' because of executive inaction and official suspicion.

One estimate from an insider at the national health department's Foreign Workforce Management Programme (FWMP) put the number at 300 equivalent to the annual output of two South African medical schools. The FWMP has issued letters of endorsement to most of these foreign qualified doctors, stating they have met a set of stringent criteria qualifying them to work in South Africa. They are married to South Africans and come mainly from Nigeria or, to a lesser extent, the Democratic Republic of Congo (DRC), putting them in double jeopardy as sceptical officials enforce a moratorium on their being hired or cite Third World country 'anti-poaching' policy agreements.

None are part of the health department-favoured 'country-to-

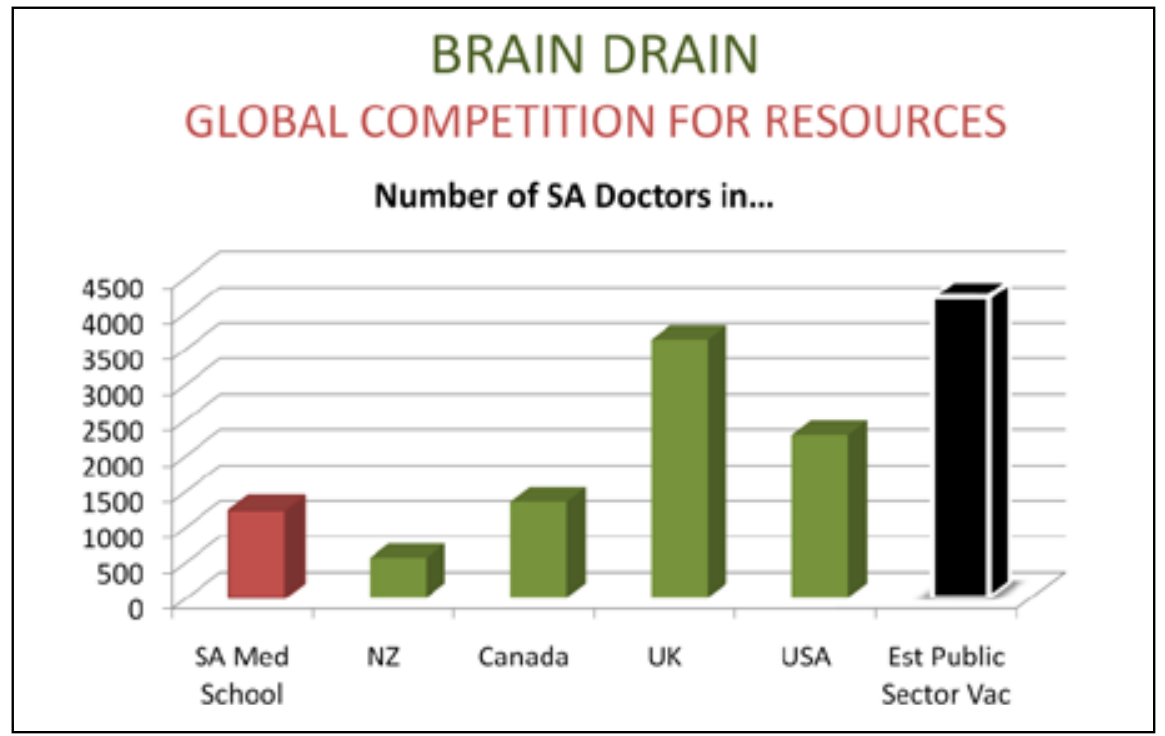

country' agreements. Exhaustive attempts to secure official confirmation of such a moratorium (on hiring foreign doctors married to South Africans) and to find out why a long-ordered review of policy on recruitment of foreign health care professionals has yet to be undertaken, proved fruitless. Izindaba's list of questions repeatedly e-mailed to the health department's communications department, while acknowledged, remained unanswered for more than two months, lending weight to the contention that officials are in a 'frozen quandary', pending an executive decision from the Minister of Health.

Calls to the direct lines of FWMP Director, Hennie Groenewald, and his deputy Nomphumelelo Zulu, went unanswered. Groenewald is known to have submitted policy redrafting proposals to his national human resources chief, Dr Percy Mahlati, for review and ministerial approval.

\section{Public Protector steps in}

The bureaucratic impasse has dragged on for so long that the Office of the Public Protector (OPP) has now assigned a senior advocate to probe the 'systemic implications' of multiple complaints to it by foreign qualified doctors married to South Africans.The OPP wants 'administrative justice' for its clients, telling Izindaba that 'all the frustrated doctors want is a simple yes or no answer'.

The bureaucratic impasse has dragged on for so long that the Office of the Public

Protector (OPP) has now assigned a senior advocate to probe the 'systemic implications' of multiple complaints to it by foreign qualified doctors married

to South Africans.The OPP wants 'administrative justice' for its clients, telling Izindaba that 'all the frustrated doctors want is a simple yes or no answer'. 
'Without the so-called

"banned" doctors our rural hospitals would collapse,' she emphasised. An estimated $15 \%$ of South Africa's public health sector posts are filled by foreign qualified doctors, making nonsense of the official $5 \%$ ceiling.

An Izindaba source in the OPP added: 'It's astonishing that this is not seen as a priority, given that a significant portion of these doctors could legitimately be helping relieve the pressure on their overworked local colleagues, never mind helping treat the thousands of economic and political African refugees denied proper treatment back home'.

Yet the moratorium floats on in a vacuum of executive decision making. At the stroke of a pen Dr Aaron Motsoaledi can mitigate the ongoing doctor shortage crisis, but risks violating South Africa's non-poaching agreements (included in SADC protocols, $\mathrm{WHO}$ non-poaching agreements and the NEPAD health strategy) and admitting that another policy, putting a $5 \%$ hiring ceiling on foreign qualified health care workers, is now moribund.

Officials in Home Affairs and the FWMP are meanwhile highly suspicious of the motives or legitimacy of foreigners married to South Africans, given the number of syndicates believed to be operating within and outside of officialdom. The cost of this suspicion is that 'legitimate' foreign qualified doctors are being unfairly penalised. Izindaba sources said the Nigerians in particular were 'all being painted with the same brush'.

One practical alternative being punted by some within the NGO recruitment community is to re-design South Africa's Third World antipoaching policy by creating 'exceptions' for qualifying foreign health care workers with permanent residence status and upping the $5 \%$ ceiling quota.

\section{Vital pharmacists and nurses also affected}

Key staffers at Africa Health Placements (AHP), the country's leading recruitment and placement $\mathrm{NGO}$, confirmed that the policy tangle was an obstacle, adding that the moratorium applied not only to hiring doctors but also desperately needed nurses and pharmacists married to South Africans. They agreed that the moratorium needed 'urgent sorting out'.

An added complication this year is the freezing of clinical posts by provinces that have mismanaged themselves into billion rand deficits, such as KwaZulu-Natal and the Free State. In stark contrast, the Eastern Cape declared itself 'open for hiring', with more than half of its funded posts for chief medical officers currently vacant.

Tracey Hudson, the AHP's KwaZulu office chief, said that whenever such a post was filled it was invariably by an experienced foreign qualified doctor, especially in the more remote hospitals. 'Without the so-called "banned" doctors our rural hospitals would collapse,' she emphasised.

An estimated 15\% of South Africa's public health sector posts are filled by foreign qualified doctors, making nonsense of the official 5\% ceiling. This reality is $10 \%$ below the equivalent norm applied by the USA and the UK (25\%). AHP last year placed 237 foreign doctors in struggling rural facilities, seven times as many rural doctors as all the medical schools combined. Since mid-2005 they have placed more than

\section{PRODUCTION: A SIMPLE TREND}

\section{South African Medical School's Annual Static Intake - Stable since the 1970's}

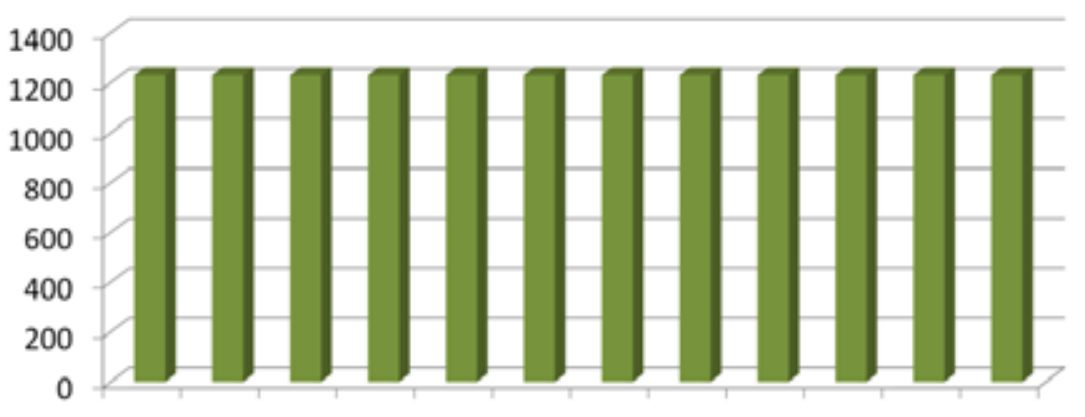

199619971998199920002001200220032004200520062007 
the NGO, Africa Health Placements' highly successful and efficient KwaZulu-Natal office as representing 'best practice'.

The AHP'S national manager, Dr Saul Kornik, said last month that wherever they found 'willing and able' provincial administrations and hospital managers, a 'process of best practice' could be implemented. 'We've now got things working in North West and Limpopo indaba provinces as well,' he said.

One goal reportedly agreed to by all parties at the April 2008 indaba was that $80 \%$ of successful applicants for state sector placement would be placed within a year, something the official wall of silence has denied assessment of for Izindaba readers.

Described at the time as 'a great success' in helping the otherwise 'recruitment-passive' health department know where and how to place foreign doctors and nurses, many of the ambitious workshop goals remain a distant dream.

A European Union (EU) grant has enabled the hiring of four call centre agents, two at the FWMP and two at Academic Health Services (which handles community service and internship for non-South Africans) but the IT improvement project died an early death because of budget constraints.

\section{New policy directive sought - but not found}

In its 2009 annual report (Strategic Objectives and Plan), the Department of Health confessed that an intended review of its 'poaching' policy had yet to be undertaken - even though the original target date for this was October 2008. Under the heading 'HR development and management' is a review of policy on recruitment of foreign health professionals.

The 'status report' here has the following entry: 'a review of the recruitment policy not yet undertaken... a policy directive regarding foreign health professionals who obtain temporary residence before applying for employment will be sought'.

Izindaba's OPP legal source said that any new regulations could only be drafted once a 'reviewed' policy was finalised by the health minister. 'We have court rulings which say (foreign health care workers) have the right of temporary residence and the right to earn an income by working in South Africa in order to fulfil their duty of support to local spouses, pending an application for permanent residence,' he added pointedly. (He was referring to the August 2009 court ruling giving several Nigerian doctors married to South Africans endorsement and placement at South African hospitals).

He said he had official documentation in front of him in which foreign qualified doctors were officially told (in March 2008) that applications from those married to South African citizens would be 'suspended'.

A spokesperson for the Health Profession Council of South Africa

\section{PRODUCTION:}

\section{A SIMPLE TREND}

BUT: African Medical School's Annual Static Intake - Stable since

- Growing population

- Increasing brain drain

- Changing demographics impacting

800 on number of "doctor hours"

400 - Number of final graduates is

200 declining

- Growing disease burden
199619971998199920002001200220032004200520062007
Said one Izindaba health department source: 'Those not washing cars are selling sweets and cigarettes on our street corners'.

(HPCSA), Mrs Bertha Peters-Scheepers, said there were currently 52 applications from foreign qualified doctors who either did not qualify for admission to the Board examination or did not qualify to be registered as medical practitioners because of non-compliance with HPCSA requirements. All would be dealt with on a 'case by case basis'.

She said that late last year regulations relating to the registration of persons who held qualifications 'not prescribed for registration' were promulgated, giving 'clear guidelines' to all concerned. The OPP advocate responded that he was working only with people who had already cleared all the qualifying hurdles, but were now being blocked on placement.

Professor Jannie Hugo, head of Family Medicine at the University of Pretoria and a member of the AHP's advisory board, said the quality of the DRC candidates for the HPCSA board exam was generally 'quite low' but the Nigerians had a higher pass rate. 'I think the $5 \%$ ceiling is a real problem and I can see the logic behind the developing countries' anti-poaching policy, but people get caught between international and individual fairness,' he added. The majority of foreign doctor applicants are from African countries.

\section{Status of country agreements}

The health department relies mainly on country-to-country agreements to help plug the worst staffing gaps (mostly at rural hospitals) and in August last year, after clinical review, renewed the threeyear contracts of 21 out of 31 Iranians.

Another 100 Tunisian country-tocountry agreement doctors, most of them highly sought-after specialists, come up for clinical review next December, with Russia, Bulgaria and Egypt now in the health department's sights.

Scores of Cuban doctors, among the first to work in South Africa under 
country-to-country agreements, won permanent residence rights after protracted court cases.

The FWMP and Home Affairs subsequently put their heads together and tightened the legal screws. The agreements are now called 'treaty permits', which can be revoked with little legal recourse, giving applicants two to three months to 'pack their bags'.

The sub-optimal recruitment by the national health department (provinces advertise vacant posts in linked health department websites of dramatically varying usefulness and in some national and local newspapers, but not in doctor-specific publications), remains a concern

A Google analysis of the Health and Medical Publishing Group's (SAMJ being the flagship) own professional ads (the vast majority being overseas recruitment agencies and some AHP) reveals 5009 'hits' from 84 countries between 28 January 2009 and 28 January this year, with $58.28 \%$ of them 'new visits', and an average viewing time of four minutes (considered 'serious customers' in IT-speak).

Of the 'hits' 3504 were by South Africans (predictor of an ongoing exodus?), 484 by citizens of the UK, 195 by Canadians, 136 by Irish viewers, 107 by Australians and 70 by US citizens, dropping to the mid-40s (China, India, the Netherlands) and below for the remaining countries.

Since the professional ads website ${ }^{2}$ went online on 1 June last year (running across 12 existing HMPG medical publications), it has attracted 5000 visits and is now running at 1000 visits per month with an average of 8.73 pages read per visit. These data provide a stark illustration of the global mobility of doctors and the untapped advertising potential for South Africa's health departments.

Meanwhile local health care service delivery remains in crisis, and legitimate, willing and highly qualified Third World health care professionals languish in official limbo.

Said one Izindaba health department source: 'Those not washing cars are selling sweets and cigarettes on our street corners'.

\section{Chris Bateman}

Bateman C Veil of silence falls over Health Dept kickback probe. S Afr Med J 2009; 12: 626-627.

2. www.professionalads.co.za Graphs courtesy of AHP, Rural Health Initiative and the Foundation for Professional Development.

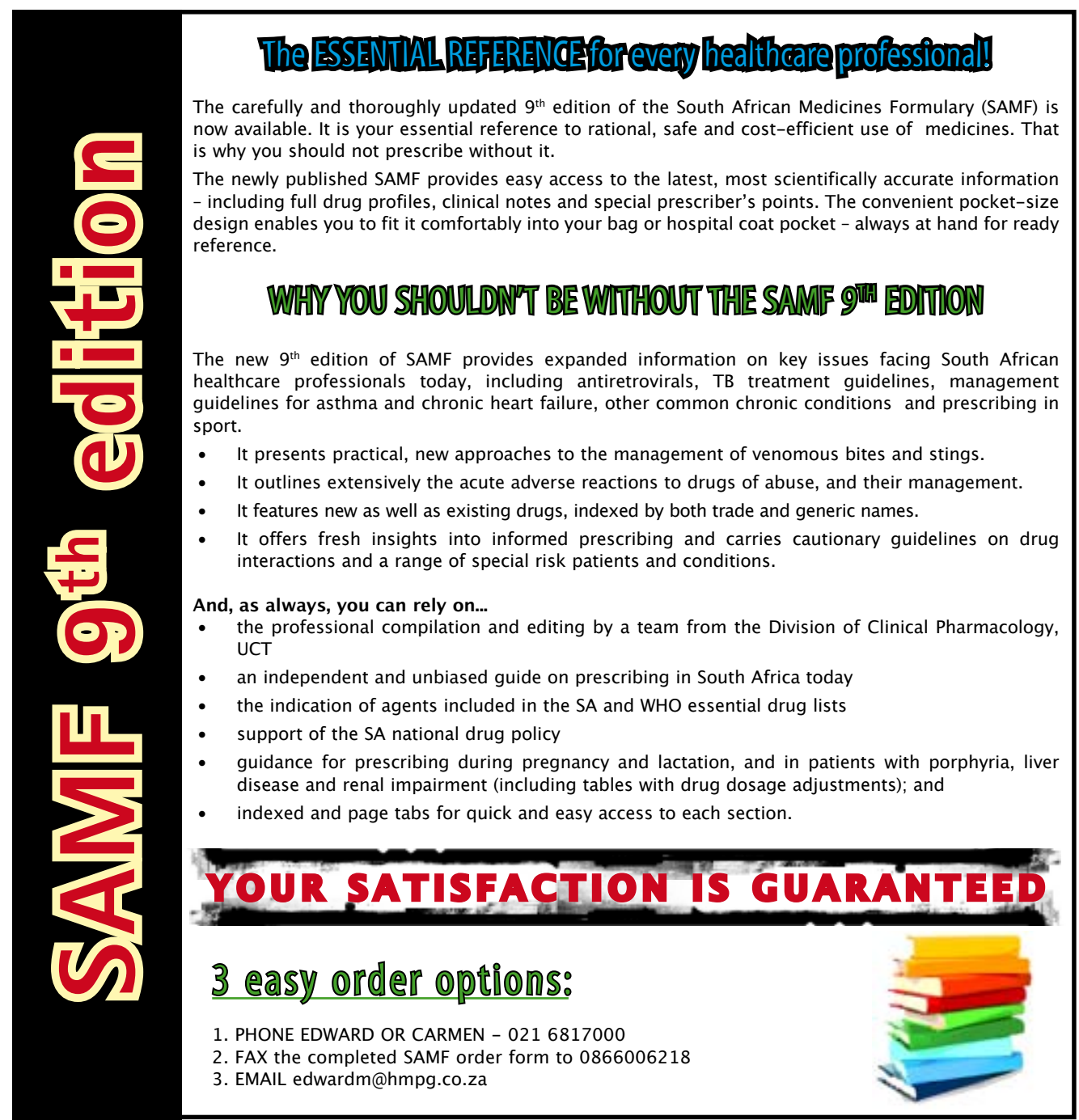

